\title{
Eficiência de óleos essenciais de canela e cravo-da-índia como sanitizantes na indústria de alimentos ${ }^{1}$
}

\author{
Carolina Beraldo ${ }^{2}$, Natália Silva Daneluzzi² ${ }^{2}$ Juliana Scanavacca ${ }^{2}$, \\ Júlio Toshimi Doyama ${ }^{3}$, Ary Fernandes Júnior ${ }^{4}$, Cristiane Mengue Feniman Moritz ${ }^{2}$
}

\begin{abstract}
Efficiency of cinnamon and clove essential oils as sanitizers in the food industry

The traditional chemical sanitizers used in the food industry have the disadvantage of a possible development of bacterial resistance and adaptation, interfering with their minimum bactericidal efficiency. Essential oils with antimicrobial activity arouse great interest in the food industry for their possible use as active ingredients of sanitizers. This study aimed to determine the minimum inhibitory concentration (MIC) of cinnamon and clove essential oils (EOs) against Gram-positive (Staphylococcus aureus and Listeriamono cytogenes) and Gramnegative (Escherichia coli and Salmonella sp.) bacteria, as well as compare it with the MIC of sodium hypochlorite, and to determine the minimum bactericidal concentration (MBC) of EOs for L. monocytogenes. The microdilution method was used and the EOs were chemically characterized by gas chromatography mass spectrometry. The main components of the cinnamon and clove EOs were respectively cinnamaldehyde (67.58\%) and eugenol (77.58\%). The cinnamon EO MIC was $0.04 \%$ for Grampositive bacteria and $<0.02 \%$ for Gram-negative bacteria. The clove EO showed MIC of $0.04 \%$ for Salmonella sp., $0.06 \%$ for E. coli and $S$. aureus and $0.08 \%$ for L. monocytogenes. For all bacteria tested the sodium hypochlorite MIC was $>0.2 \%$. The $\mathrm{MBC}$ for L. monocytogenes of the clove EO was $0.18 \%$, while the cinnamon $\mathrm{EO}$ distinguished itself for presenting $\mathrm{MBC}<0.02 \%$, demonstrating the possibility of using these EOs, especially the cinnamon one, as active principles of sanitizers.
\end{abstract}

KEY-WORDS: Cinnamomum zeylanicum; Syzygium aromaticum; microorganism control.

\section{INTRODUÇÃO}

Os óleos essenciais (OEs) de plantas são comumente comercializados em função de sua capacidade aromatizante. No entanto, têm des-

\section{RESUMO}

Os sanitizantes químicos tradicionais utilizados na indústria de alimentos apresentam, como desvantagem, o possível desenvolvimento de resistência e adaptação bacteriana, interferindo na eficiência bactericida mínima destes produtos. Os óleos essenciais com atividade antimicrobiana despertam grande interesse na indústria de alimentos, pela possível utilização como princípios ativos de sanitizantes. Esta pesquisa objetivou determinar a concentração inibitória mínima (CIM) dos óleos essenciais (OEs) de cravo-da-índia e canela contra bactérias Gram positivas (Staphylococcus aureus e Listeriamono cytogenes) e Gram negativas (Escherichia coli e Salmonella sp.) e compará-la com a CIM do hipoclorito de sódio, além de determinar a concentração bactericida mínima (CBM) dos OEs para L. monocytogenes. Foi utilizado o método da microdiluição e os OEs foram caracterizados, quimicamente, por cromatografia gasosa - espectrometria de massa. Os componentes principais dos OEs de canela e cravo-da-índia foram o cinamaldeído (67,58\%) e o eugenol $(77,58 \%)$, respectivamente. A CIM do OE de canela foi de $0,04 \%$, para as bactérias Gram positivas, e $<0,02 \%$, para a bactérias Gram negativas. O OE de cravo-da-índia teve CIM de $0,04 \%$ para Salmonella sp., 0,06\% para E. coli e $S$. aureus e $0,08 \%$ para L. monocytogenes. Para todas as bactérias testadas, a CIM do hipoclorito de sódio foi $>0,2 \%$. A CBM para L. monocytogenes, no OE de cravo-da-índia, foi de $0,18 \%$ e o OE de canela destacou-se por apresentar CBM $<0,02 \%$, demonstrando a possibilidade do uso destes OEs, principalmente o de canela, como princípios ativos de sanitizantes.

PALAVRAS-CHAVE: Cinnamomum zeylanicum; Syzygium aromaticum; controle de micro-organismos.

pertado grande interesse, devido às propriedades funcionais que, também, apresentam como antimicrobianos, principalmente para a aplicação em alimentos. Entretanto, a utilização de OEs como antimicrobianos aplicados diretamente em

1. Trabalho recebido em mar./2013 e aceito para publicação em nov./2013 (nº registro: PAT 23250).

2. Universidade Estadual de Maringá (UEM), Departamento de Tecnologia, Umuarama, PR, Brasil.

E-mails: carolinaberaldo@hotmail.com,natdaneluzzi@hotmail.com,juscan0811@gmail.com,crisfeniman@yahoo.com.br.

3. Universidade Estadual Paulista "Júlio de Mesquita Filho" (Unesp), Instituto de Biociências, Departamento de Química e Bioquímica, Botucatu, SP, Brasil.E-mail: julio@ibb.unesp.br.

4. Universidade Estadual Paulista "Júlio de Mesquita Filho" (Unesp), Instituto de Biociências, Departamento de Microbiologia e Imunologia, Botucatu, SP, Brasil. E-mail: ary@ibb.unesp.br. 
alimentos ainda encontra obstáculos em sua real aplicação industrial.

Embora os OEs e seus componentes sejam altamente eficientes em testes in vitro, contra patógenos e micro-organismos deterioradores de origem alimentar, o mesmo efeito foi encontrado somente quando concentrações maiores de OEs foram utilizadas em alimentos, o que implicou em um impacto sensorial, por exceder o limite aceitável (Burt 2004). Assim, a possibilidade de aplicar os OEs como antimicrobianos na indústria de alimentos, na função de sanitizantes, desperta grande interesse na exploração desta propriedade tecnológica dos mesmos.

Os sanitizantes químicos tradicionais utilizados na indústria de alimentos apresentam, como desvantagem, o possível desenvolvimento de resistência e adaptação bacteriana, interferindo na eficiência bactericida mínima destes. Por outro lado, a preparação de soluções sanitizantes, que se encontram concentradas, inicialmente, envolve riscos ocupacionais para os manipuladores (Issa-Zacharia et al. 2010).

Em vegetais minimamente processados, o cloro é largamente utilizado como sanitizante. Entretanto, recentes surtos associados à contaminação por patógenos provenientes de vegetais minimamente processados trazem à tona a discussão sobre a eficiência do tratamento com cloro, na obtenção de produtos seguros (Ölmez \& Kretzschmar 2009). Além disto, há o risco de formação de produtos indesenjáveis, por meio de reações com a matéria orgânica, o que pode levar, futuramente, a novas restrições regulamentadoras. Consequentemente, a indústria de processamento mínimo busca alternativas seguras (Arts et al. 2009).

A presente pesquisa objetivou determinar a concentração inibitória mínima (CIM) dos óleos essenciais (OEs) de cravo-da-índia e canela contra bactérias Gram positivas (Staphylococcus aureus e Listeriamono cytogenes) e Gram negativas (Escherichia coli e Salmonella sp.) e compará-la com a CIM do hipoclorito de sódio, além de determinar a concentração bactericida mínima (CBM) dos OEs para L. monocytogenes.

\section{MATERIAL E MÉTODOS}

O experimento foi realizado em novembro de 2012, com OEs concedidos pelo Laboratório de Produtos Naturais do Departamento de Microbiologia e Imunologia, e a caracterização química realizada no Departamento de Química e Bioquímica, ambos no Instituto de Biociências da Universidade Estadual Paulista "Júlio de Mesquita Filho", em Botucatu (SP). As determinações das concentrações inibitórias mínima e bactericida foram realizadas no Laboratório de Microbiologia do Departamento de Tecnologia da Universidade Estadual de Maringá, em Umuarama (PR).

Foram utilizados OEs de canela (Cinnamomum zeylanicum) e cravo-da-índia (Syzygium aromaticum), os quais foram extraídos por arraste de vapor, em destilador para produção de OEs (modelo MA480, Marconi). A caracterização química foi realizada em cromatógrafo gasoso acoplado a espectrômetro de massa (CG-EM) (modelo QP5050A, Shimazu), no qual foi utilizada uma coluna capilar CBP-5 de $50 \mathrm{~m}$ de comprimento, com diâmetro interno de $0,25 \mathrm{~mm}$ e $0,25 \mathrm{~mm}$ de espessura do filme. A temperatura do injetor e da interface foram de $250^{\circ} \mathrm{C}$. O detector foi operado em modo Electron Impact (EI), a $70 \mathrm{eV}$, e utilizou-se hélio, como gás de arraste.

As condições cromatográficas para o $\mathrm{OE}$ de canela foram temperatura inicial de $60^{\circ} \mathrm{C}$, aquecimento até $160^{\circ} \mathrm{C}$ (taxa de $3^{\circ} \mathrm{C} \mathrm{min.}{ }^{-1}$ ), aquecimento até $220^{\circ} \mathrm{C}$ (taxa de $15^{\circ} \mathrm{C} \mathrm{min.}{ }^{-1}$ ) e manutenção desta temperatura por 20 minutos. Para o $\mathrm{OE}$ de cravo-da-índia, a temperatura inicial foi de $50^{\circ} \mathrm{C}$ e o aquecimento até $180^{\circ} \mathrm{C}\left(\right.$ taxa de $\left.3^{\circ} \mathrm{C} \mathrm{min}^{-1}\right)$, com manutenção desta temperatura por 40 minutos. A identificação dos componentes dos OEs foi feita com base na biblioteca NIST (National Institute of Standards and Technology, MD,USA), para análise dos espectros de massas, e, também, em dados da literatura (Adams 1989).

Foram utilizadas cepas de Escherichia coli ATCC 11229, Salmonella sp. ATCC 13314, Staphylococcus aureus ATCC 14458 e Listeriamono cytogenes ATCC 7644, obtidas da coleção de micro-organismos de referência da Fundação Oswaldo Cruz (Rio de Janeiro, Brasil). As células liofilizadas foram recuperadas previamente por inoculação em meio Brain Heart Infusion (BHI-Difco) e mantidas em tubos estoques de Triptic Soy Agar (TSA-Difco). A partir das culturas estoques, cada bactéria foi inoculada em $3 \mathrm{~mL}$ de caldo BHI, sendo este incubado a $35^{\circ} \mathrm{C}$, por 48 horas.

Os testes foram efetuados em duplicata, utilizando-se a metodologia da microdiluição em microplacas de ELISA (CLSI/NCCLS 2005), com caldo BHI adicionado de $0,5 \%$ de Tween 80 . Foram testados os OEs de canela e cravo-da-índia, junta- 
mente com o hipoclorito de sódio $(\mathrm{NaOCl})$ solução $1 \%$, diluídos nas concentrações de $0,02 \% ; 0,04 \%$; $0,06 \% ; 0,08 \% ; 0,10 \% ; 0,12 \% ; 0,14 \% ; 0,16 \% ; 0,18 \%$ e $0,20 \%(\mathrm{v} / \mathrm{v})$, em volumes finais de $200 \mu \mathrm{L}$. Foram realizados ensaios controles positivos (bactéria mais meio de cultura) e negativos (meio de cultura), além dos controles de esterilidade dos tratamentos.

Os inóculos bacterianos foram padronizados em solução salina $(0,85 \%)$, estéril na escala 0,5 de MacFarland, sendo a suspensão bacteriana de, aproximadamente, $1,5 \times 10^{8} \mathrm{UFC}^{-1}$, a partir de cultura obtida após 48 horas a $37^{\circ} \mathrm{C}$. Foram inoculados volumes de $2 \mu \mathrm{L}$ das suspensões bacterianas padronizadas, obtendo-se, assim, no volume de $200 \mu \mathrm{L}$, uma contagem inicial de cerca de $10^{6} \mathrm{UFC} \mathrm{mL}^{-1}$. O conteúdo de cada poço das microplacas foi homogeneizado individualmente, utilizando-se ponteiras de micropipeta estéreis, sendo uma ponteira para cada micro-organismo, e iniciando-se da menor para a maior concentração dos agentes testados.

A leitura das placas foi realizada após incubação a $35^{\circ} \mathrm{C}$, por 24 horas, com adição de $100 \mu \mathrm{L}$ de indicador redox (resazurina $0,01 \%$ ), sendo que a coloração azul final, em cada concentração, indicou resultado negativo e a coloração rosa resultado positivo, para o crescimento bacteriano. Neste caso, a CIM foi considerada aquela em que não houve crescimento bacteriano para a menor concentração, nas duas replicatas, após o período de incubação.

Foram preparadas placas de Petri com ágar TSA adicionado de $0,5 \%$ de Tween e os OEs. Após o preparo do ágar, estando ainda liquefeito, foram transferidos $10 \mathrm{~mL}$ para tubos de ensaio e adicionados os OEs e as mesmas concentrações de CIM, sendo, imediatamente, o ágar homogeneizado em agitador para tubos tipo vortex e vertido na placa. Após solidificação, em triplicata, as placas foram inoculadas por semeadura de superfície, com $0,1 \mathrm{~mL}$ da mesma suspensão de Listeriamono cytogenes padronizada na escala 0,5 de MacFarland, para a CIM. Todas as placas foram incubadas invertidas, a $35^{\circ} \mathrm{C}$, por 24 horas. A leitura considerou a presença de crescimento microbiano como positivo e a CBM foi considerada aquela em que não houve crescimento bacteriano para a menor concentração, nas duas replicatas.

\section{RESULTADOS E DISCUSSÃO}

Os componentes principais dos OEs de canela e cravo-da-índia foram o cinamaldeído
(67,58\% - pico 17) e o eugenol (77,58\% - pico 1), respectivamente. Os cromatogramas são apresentados na Figura 1.

O mecanismo primário de ação do eugenol, em concentração bactericida, promoveu a ruptura da membrana citoplasmática, aumentando a sua permeabilidade não específica. Esta hiperpermeabilidade promoveu o extravasamento de íons e a perda excessiva de outros componentes celulares, incluindo as proteínas intracelulares, resultando, finalmente, em morte celular (Devi et al. 2010).

Os valores das CIMs estão apresentados na Tabela 1. As CIMs do OE de canela foram menores para as bactérias Gram negativas (inferior a 0,02\%, para ambas as bactérias) que para as Gram positivas $(0,04 \%$, para ambas as bactérias). Oussalah et al. (2007) também encontraram menores CIMs para os mesmos gêneros bacterianos de Gram negativas, utilizando outra espécie de canela, mas com percentagem aproximada $(65,00 \%)$ do componente majoritário do OE deste estudo $(67,58 \%)$, o cinamaldeído.
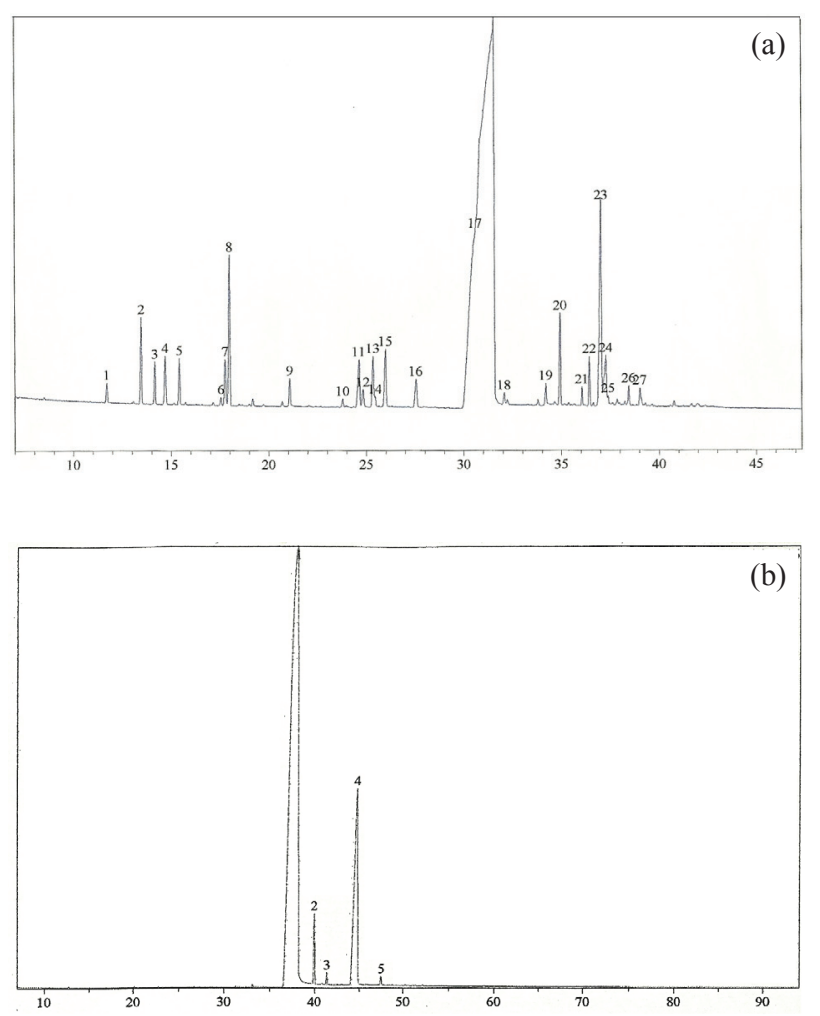

Figura 1. Cromatogramas obtidos para os óleos essenciais de canela (a) e cravo-da-índia (b) e usados para a identificação dos compostos, por meio de cromatografia gasosa - espectrometria de massa (Botucatu, SP, 2012). 
Tabela 1. Concentração inibitória mínima (CIM) do hipoclorito de sódio, óleo essencial (OE) de canela (Cinnamomum zeylanicum) e cravo-da-índia (Syzygium aromaticum) (Umuarama, PR, 2012).

\begin{tabular}{lccc}
\hline \multicolumn{1}{c}{ Bactéria } & OE de canela & OE de cravo-da-índia & Hipoclorito de sódio \\
\hline Staphylococcus aureus ATCC 14458 & $0,04 \%$ & $0,06 \%$ & $>0,2 \%$ \\
Listeria monocytogenes ATCC 7644 & $0,04 \%$ & $0,08 \%$ & $>0,2 \%$ \\
Escherichia coli ATCC 11229 & $<0,02 \%$ & $0,06 \%$ & $>0,2 \%$ \\
Salmonella sp. ATCC 13314 & $<0,02 \%$ & $0,04 \%$ & $>0,2 \%$ \\
\hline
\end{tabular}

Foram encontradas diferentes CIMs para o OE de cravo-da-índia, na repetição do experimento. Todos os valores foram menores que a CIM $(0,9 \%)$ deste OE encontrada por Barbosa et al. (2009), para as mesmas bactérias. Entretanto, deve-se considerar que esta diferença de CIM pode ter sido observada devido às diferentes linhagens de bactérias testadas e, também, ao estágio de crescimento das mesmas.

Para todas as bactérias utilizadas nessa repetição, Gram positivas e negativas, as concentrações de hipoclorito de sódio testadas não apresentaram atividade antimicrobiana. Assim, a CIM foi considerada maior que $0,2 \%$, para este sanitizante, neste estudo. Entretanto, deve-se considerar que, no método utilizado, foi realizada a diluição do hipoclorito de sódio em caldo BHI, o que, possivelmente, provocou a inativação do cloro, em função da matéria orgânica presente no meio de cultura.

$\mathrm{Na}$ determinação da CBM para Listeriamono cytogenes, não foi observado crescimento nas placas com a menor concentração de OE de canela, sendo, então, considerada a CBM menor que $0,02 \%$, para este óleo. Nas placas com adição de OE de cravo-da-índia, verificou-se que, na concentração de $0,18 \%$, não houve crescimento em nenhuma das replicatas, sendo este valor considerado a CBM.

Utilizando o mesmo método de microdiluição em placas, Moreira et al. (2005) determinaram a concentração de $0,3 \%$ de OE de cravo-da-índia como a CBM para E. coli. Deve-se considerar que a CBM encontrada para o OE, neste estudo, foi $40 \%$ menor que o resultado obtido pelos autores citados, além de que, normalmente, os OEs apresentam capacidade bactericida para bactérias Gram negativas em concentrações menores que para as Gram positivas. Esta diferença de CBM poderia ser explicada pela variação na composição química entre os óleos extraídos, entretanto, no estudo citado, não foi realizada a caracterização química, para comparação. Pereira et al. (2008) utilizaram o método de difusão em disco e verificaram a formação de halo de inbição de $1,0 \mathrm{~cm}$, para $S$. aureus, a partir da concentração de $0,1 \%$.

Sandasi et al. (2008) verificaram que componentes de OEs foram capazes de reduzir a formação de biofilmes de Listeriamono cytogenes. Oliveira et al. (2010) aplicaram tratamentos sanitizantes por 60 minutos de contato com solução à base de OEs de Cymbopogon citratus e C. nardus, sendo observada a capacidade de estas soluções reduzirirem, em 100\% (5,64 Log UFC $\left.\mathrm{cm}^{-2}\right)$, o número de células aderidas na superfície de aço inoxidável por tratamento de formação de biofilmes de L. monocytogenes, por 240 horas.

Diante dos resultados obtidos neste estudo e de outros dados da literatura científica, ressalta-se a importância da continuidade de pesquisas com enfoque na aplicabilidade dos OEs como princínpios ativos para sanitizantes, como uma nova alternativa para a indústria de alimentos. Entretanto, evidencia-se que, para a aplicação de soluções sanitizantes em equipamentos e diretamente na superfície de alimentos, como frutas e vegetais, devem ser avaliadas as interferências sensoriais provocadas pelos OEs.

Outra questão que também deve ser considerada é a viabilidade de soluções sanitizantes utilizando os OEs como princípios ativos, pois há necessidade de aprimoramento do processo de obtenção dos OEs, para que ocorra redução no custo dos mesmos. No entanto, ainda que possíveis sanitizantes à base de OEs possam ter um custo maior que os sanitizantes tradicionais, é importante ressaltar que o OE de canela apresentou significativa CBM para L. monocytogenes, estando diluído em meio de cultura rico em compostos orgânicos, evidenciando promissora aplicação em ambientes propícios à formação de biofilmes, como no caso da indústria láctea.

\section{CONCLUSÕES}

1. Os OEs de canela e cravo-da-índia mostraram-se mais eficientes que o hipoclorito de sódio, na 
inibição das bactérias em estudo, utilizando-se o método da microdiluição.

2. É possível aplicar os OEs como princípios ativos de sanitizantes, em função de menores concentrações necessárias para a inibição microbiana. Todavia, faz-se necessária a continuidade de pesquisas sobre as interferências sensoriais dos OEs em alimentos.

3. O OE de canela apresentou atividade inibitória inferior a $0,02 \%$ e atividade bactericida nesta concentração, para L. monocytogenes.

\section{REFERÊNCIAS}

ADAMS, R. P. Identification of essential oils by ion trap mass spectroscopy. San Diego: Academic Press, 1989.

ARTS, F. et al. Sustainable sanitation techniques for keeping quality and safety of freshcut plant commodities. Postharvest Biology and Technology, Amsterdam, v. 51, n. 3, p. 287-296, 2009.

BARBOSA, L. N. et al. Essential oils against foodborne pathogens and spoilage bacteria in minced meat. Foodborne Pathogens and Disease, New Rochelle, v. 6, n. 6, p. 725-728, 2009.

BURT, S. Essential oils: their antibacterial properties and potential applications in foods: a review. International Journal of Food Microbiology, Amsterdam, v. 94, n. 3, p. 223-253, 2004.

CLINICAL AND LABORATORY STANDARDS INSTITUTE/ NATIONAL COMITEE FOR CLINICAL LABORATORY STANDARDS (CLSI/NCCLS). Performance standards for antimicrobial susceptibility testing: fifteenth information supplement. Wayne: CLSI/ NCCLS, 2005.

DEVI, K. P. et al. Eugenol (an essential oil of clove) acts as an antibacterial agent against Salmonella typhi by disrupting the cellular membrane. Journal of Ethnopharmacology, Amsterdam, v. 130, n. 1, p. $107-$ 115, 2010.

ISSA-ZACHARIA, A. et al. Sanitization potency of slightly acidic electrolyzed water against pure cultures of Escherichia coli and Staphylococcus aureus, in comparison with that of other food sanitizers. Food Control, Amsterdam, v. 21, n. 5, p. 740-745, 2010.

MOREIRA, M. R. et al. Inhibitory parameters of essential oils to reduce a foodborne pathogen. LWT: Food Science and Technology, Amsterdam, v. 38, n. 5, p. 565-570, 2005.

OLIVEIRA, M. M. M. et al. Disinfectant action of Cymbopogon sp. essential oils in different phases of biofilm formation by Listeria monocytogenes on stainless steel surface. Food Control, Amsterdam, v. 21, n. 4, p. 549553, 2010.

ÖLMEZ, H.; KRETZSCHMAR, U. Potential alternative disinfection methods for organic fresh-cut industry for minimizing water consumption and environmental impact. LWT: Food Science and Technology, Amsterdam, v. 42, n. 3, p. 686-693, 2009.

OUSSALAH, M. et al. Inhibitory effects of selected plant essencial oils on the growth of four pathogenic bacteria: E. coli O157:H7, SalmonellaTyphimurium, Staphylococcus aureus and Listeria monocytogenes. Food Control, Amsterdam, v. 18, n. 5, p. 414-420, 2007.

PEREIRA, A. A. et al. Caracterização química e efeito inibitório de óleos essenciais sobre o crescimento de Staphylococcus aureus e Escherichia coli. Ciência e Agrotecnologia, Lavras, v. 32, n. 3, p. 887-893, 2008.

SANDASI, M.; LEONARD, C. M.; VILJOEN, A. M. The effect of five common essential oil components on Listeria monocytogenes biofilms. Food Control, Amsterdam, v. 19, n. 11, p. 1070-1075, 2008. 